\title{
Development of technological processes using operational models.
}

\author{
Loginov Vladimir \\ Department of industrial and manufacturing engineering \\ Samara State Technical University \\ E-mail: Vladimir1995loginov@ mail.ru.
}

\author{
Matseyn Nikita \\ Department of industrial and manufacturing engineering \\ Samara State Technical University \\ E-mail: Matseyn95@gmail.com.
}

\author{
Goryainov Dmitry \\ Professor of engineering technology \\ Samara State Technical University \\ E-mail: goryinovd@yandex.ru
}

\begin{abstract}
The technique of creating a technological process was developed with the use of operational electronic models that can be applied at any enterprise with the aim of increasing the speed of technological preparation of production and simplifying the work of employees. The work on the implementation of the technique on the real aviation details has been conducted. The results of relevance were summed up and a positive outcome from the results of the method use was obtained.
\end{abstract}

Keywords - technological process, operational electronic models, control programs, technological equipment.

\section{INTRODUCTION}

The use of electronic models (EM) at the stage of design and design preparation of production, which has become the standard of modern engineering, necessitates the revision of work methods at the stage of technological preparation of production (TPP). The work on the basis of EM at the stage of TPP is mainly used in the development of control programs (CP) for CNC machines. Each company has its own peculiarities when working with EM at the stage of TPP. Analyzing machine-building enterprises of Samara, it can be concluded that in modern manufacturing, the proportion of mechanical processing on the software equipment constitutes up to $60-70 \%$ of the complexity of manufacturing details and has a tendency to rise. However, nowadays, it is not rational to completely abandon the universal equipment, at the stage of TPP, documents are created in the human-readable form, for example, sketches of operating cards and in the machinereadable form, for example, $\mathrm{CP}$ for $\mathrm{CNC}$ machines and data on material and labor standards [1].

At some enterprises and in some industries, there is a normatively fixed and consistent consequential work frame of design bureau and serial production. That means that the work of the plant begins with the transfer of design set documentation. Often technological services of the plant are not ready to accept the designer electronic model and continue working with it on the basis of the EM. There is a transition from EM to electronic drafts, and the work at the stage of TPP is built, based on the drafts. With such organization of technological processes development (TP), CNC technicians are in an uncomfortable situation because often operations with $\mathrm{CNC}$ equipment are in the middle of $\mathrm{TP}$ and it is becoming unobvious what form the workpiece that came to the operation with $\mathrm{CNC}$ will have. It often happens that, EM, coming to the operation with a CNC technician, $\mathrm{CNC}$ creates itself. Designers of the technological equipment (TE) are in the same position. In this case, CNC technology and designers mainly work with EM. This leads to a simple conclusion about the development of TP based on the EM, not on the drafts [2].

\section{THEORETICAL PREPARATION}

If we analyze the share of labor intensity in the development of a technological documentations' set on a wide-nomenclature small-scale enterprise with a large share of machining, we can see that the stage of design of technological sketches can be spent up to $70 \%$ of the time of the technologist.

There has been study conducted about the connection of computer systems that are being used for the preparation of TP (CAPP), design systems (CAD) and systems for the development of CP for CNC machines to identify improved efficiency of their joint use. The structure of the creation of the EM of TP is shown in figure 1. 


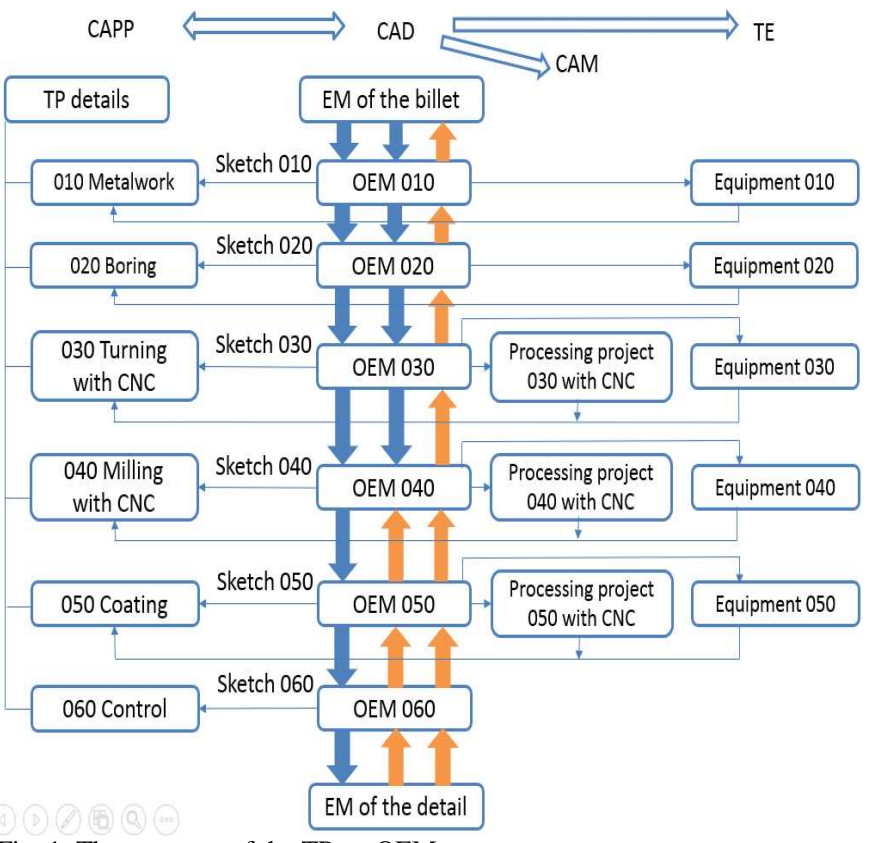

Fig. 1. The structure of the TP on OEM

In describing the graphical part of the TP operational electronic models (OEM) are taken as a basis. In the TP, all OEM must be associatively connected to each other, which will allow design changes to be made across the entire TP automatically. To build an associative OEM we can distinguish three patterns can be associative associated models:

1) From the billet to a detail

2) From a detail to the billet

3) Mixed

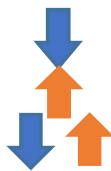

At the initial stage, the structure of the through TP is created, including all processing and special TP. The structure of TP is created in the CAPP. In parallel or on the ready structure of $\mathrm{TP}$, the graphic description of a condition of preparation on operations in the form of EM in CAD-system is created.

When creating the OEM, tools for associative geometry copying are used and, thus, a set of associativity linked the EM billet is obtained. Associative communication is needed primarily to reduce errors associated with the correct distribution of allowance on surfaces processed for several operations and for rapid change. OEM are created both for form-building operations and for non-form-building ones; for operations on universal equipment and for operations performed on CNC equipment. Since the CAPP does not provide for work with EM, associative operational sketches are created on the OEM.

In parallel, or after completing the creation of the OEM package, operations on CNC equipment, as well as service stations, can be designed. When machining on a CNC machine, the current OEM will be the billet being processed on the operation, and the previous OEM will be the billet. The calculation and technological maps (TM), which are created during the development of CNC operations, are also constructed as associative sketches for the OEM.

With a small increase of time in the preparation of the operating billet (OB) during the creation of the structure, increases the efficiency of CNC technologists and designers of TE.

The structure of the TP is the main object, to which other objects are attached - OB, TE packages, processing projects in the CAM system, etc. At the same time, it is possible to organize effective work of specialists in the above scheme using PDM-system.

For a clear example of the effectiveness of the method of developing a TP on the OEM, let us consider the structure of the creation of the "Hydraulic cylinder cover".

The choice of software is one of the main tasks needed to create EM. Using 3D modeling is impossible without the use of software products that have a mechanism for 3D modeling, i.e. construction and correction of EM [3].

Today, there is a wide range of graphic editors and programs for geometric modeling. Let us consider the options for organizing the environment for the development of end-toend TP based on EM (Fig. 2).

\begin{tabular}{|c|c|c|}
\hline CAPP & $C A D$ & $C A M$ \\
\hline Vertical & $\begin{array}{l}\text { Compas-3D } \\
\text { Compas-Graphic }\end{array}+$ & SprutCAM \\
\hline Timeline & $\begin{array}{l}\text { Inventor, Compas, NX, } \\
\text { SolidWorks }\end{array}$ & $\begin{array}{lr}\text { Does } & \text { not } \\
\text { depend } & \text { on } \\
\text { Timeline. } & \end{array}$ \\
\hline $\begin{array}{l}\text { Adem } \\
\text { CAPP }\end{array}$ & Adem $C A D$ & Adem CAM \\
\hline Sprut-TP & $\begin{array}{l}\text { Wide } \\
\text { (Inventor, } \quad \text { spectrum } \\
N X, \quad \text { Compas, } \\
\text { m.n.) }\end{array}$ & $\begin{array}{lr}\text { Any. Does not } \\
\text { depend } & \text { on } \\
\text { Sprut-TP } & \end{array}$ \\
\hline Teamcenter & $\begin{array}{l}N X \text { is recommended, } \\
\text { although data can be } \\
\text { stored in any formats }\end{array}$ & $\begin{array}{l}N X-C A M \text { is } \\
\text { recommended, } \\
\text { but any }\end{array}$ \\
\hline TechnoPro & $\begin{array}{l}\text { Wide } \\
\text { (Inventor, } \quad \text { spectrum } \\
\text { NX, Sompas, } \\
\text { m.n.) }\end{array}$ & $\begin{array}{lr}\text { Any. Does not } \\
\text { depend } & \text { on } \\
\text { TechnoPro } & \end{array}$ \\
\hline
\end{tabular}

Fig. 2. Organization of the TP development environment. 


\section{PRACTICAL APPLICATION}

As a basis for CAPP, we will take "Teamcenter", and as a CAD-system we will use the "Siemens NX" system [5]. The operations of adding or removing the allowance on the OEM are performed by both synchronous simulation operations and simple drawing and rotation operations, which will allow creating OEM and associative sketches much more professionally, easier and quicker than creating sketches "manually", which takes an order of magnitude that is longer and entails inaccuracies associated with the human factor.

Figure 3 shows the stages of the development of the TP in the "Siemens NX" system of the "Hydraulic Cylinder Cover" detail. The construction method is chosen mixed for the possibility of changing models with the help of associative links both changing the billet and the part. EMD is developed with application of technical conditions in accordance with GOST 2.052. The billet, in our case forging, is built on this model, adding allowances and allowances on the surface of the part, in accordance with GOST 7829-70. The figure shows the OEM operations related to machining, which are used to build technological sketches, as well as models necessary for programmers to write $\mathrm{CP}$ for $\mathrm{CNC}$ machines and designers of technological equipment [4].

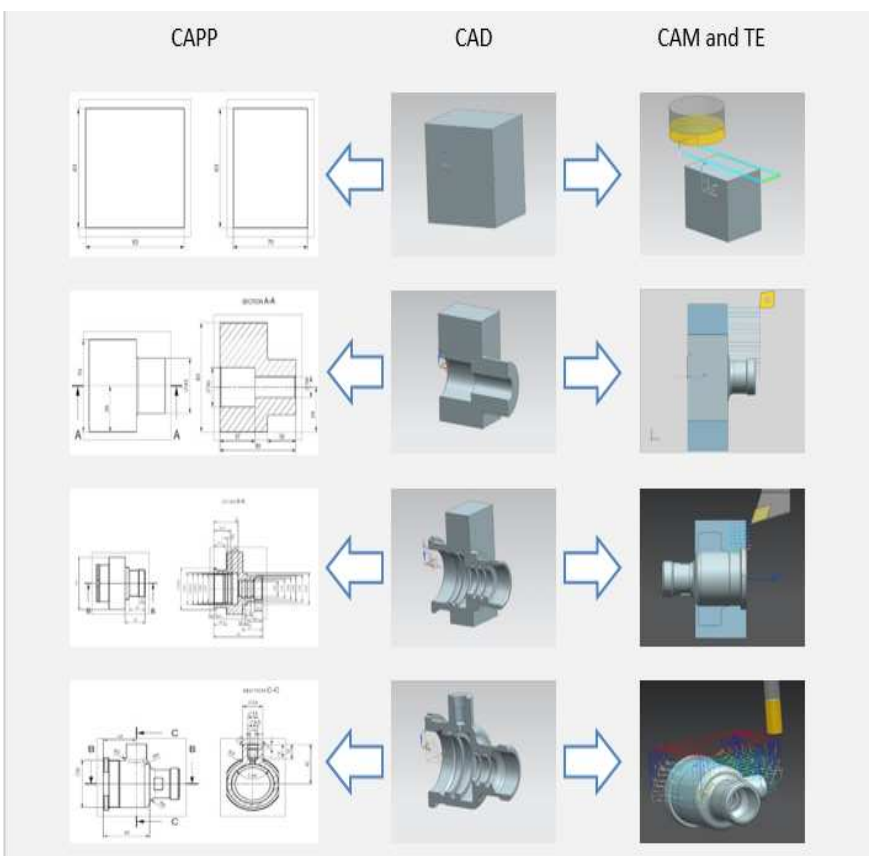

Fig.3. Stages of development of TP in the Siemens NX system.

The technique considered by the examples will allow effectively developing and carrying out changes in the TP of various complexities on the basis of the OEM.

Despite the many advantages of an OEM, there may be some shortcomings that require additional influence on the overall economic effect:

1. The time spent creating an OEM for each TP operation, binding dimensions and associative links.
2. Training of technologists owning both CAPP and 3D CAD systems.

3. Provision of workplaces of technologists with software products necessary for working with the OEM.

These shortcomings can be solved by appropriate training of personnel and, most importantly, by the correct configuration of a single information environment of the enterprise.

\section{CONCLUSION}

The method of using the OEM for creating a TP can be considered as a way of developing traditional methods for developing a TP. For the details of the "Hydraulic Cylinder Cover", OEM have been created, which allow one to obtain drawings for technologists, and models necessary for programmers of CNC machines and designers of technological equipment. It is possible to see that the technique described in the article can be successfully applied in practice and, despite the difficulties of its implementation, gives a positive effect, shortening the time at the TPP and minimizing the reception of marriage by excluding the human factor when creating sketches.

\section{REFERENCES}

[1] D. Kulikov, Technique of automated design of operating billets in the environment of the CAD system, Saint Petersburg, 2016, pp.121-123.

[2] E. Yablochnikov, D. Kulikov, V. Molochnik, Modeling of devices, systems and production processes, St. Petersburg, 2008, pp.73-79.

[3] Kunwu Lee, Fundamentals of CAD, CAD / CAM / CAE - St. Petersburg, 2004, pp.156-157.

[4] Y. Danilov, I. Artamonov, Practical use of NX, Moscow: DMK Press, 2011, p.332.

[5] D. Torop, V. Terlikov, Teamcenter, Start of work, Moscow: DMK Press, 2011, p.280.

[6] D. Kulikov, N. Shuval-Sergeev, «Design operational billet using a CAD- systems», St. Petersburg, 2010, pp. 42-46.

[7] V. Khrabrov, Design features of the operating pieces in CAD/CAM systems, St. Petersburg, 2006, pp. 219-223.

[8] V. Babanin, Parametric modeling of operational billet, St. Petersburg, 2016, p. 22.

[9] D. Kulikov, A. Voropaev, A. Ernst "The synthesis of the operating parts at the design process," St. Petersburg 2017, pp. 390-394.

[10] M. Strzhemechny, Simulation of turning operations of parts on cnc machines using CAD/CAM system, Moscow, 2016, p. 21.

[11] P. Vedmid, The programming in NX CAM, Moscow: DMK Press, 2012, p. 216

[12] I. Artamonov, P. Goncharov, NX Advanced Simulation. Practical guide, Moscow: DMK Press, 2014, p. 283.

[13] A. Torov, Teamcenter, Start of work - Siemens Product Lifecycle Management Software Inc., 2014, p.160.

[14] M. Belashov, The design of operating of technological processes on the basis of automation of analysis of functional relationships, Penza, 2009, p. 23.

[15] E. Shirokih, T. Moroz, Mechanical engineering: designing of technological processes of mechanical processing, Moscow, 2014, p. 280. 